\title{
Effect of Capillary Water Absorption on Electrical Resistivity of Concrete with Coal Gangue Ceramsite as Coarse Aggregates
}

\author{
Dong Li $\mathbb{D}^{\text {, }}$, Shi Liu $\mathbb{D}$, and Haiqing Liu \\ College of Civil Engineering, Liaoning Technical University, Fuxin, Liaoning, China \\ Correspondence should be addressed to Shi Liu; liushi@lntu.edu.cn
}

Received 6 December 2020; Revised 12 April 2021; Accepted 22 April 2021; Published 3 May 2021

Academic Editor: Hailing Kong

Copyright $\odot 2021$ Dong Li et al. This is an open access article distributed under the Creative Commons Attribution License, which permits unrestricted use, distribution, and reproduction in any medium, provided the original work is properly cited.

\begin{abstract}
This study intends to access the influence of the capillary action on electrical property of the concrete containing the coal gangue ceramsite. For this purpose, four kinds of concrete samples were prepared; the coal gangue ceramsite was adopted at four volume ratios of $0 \%, 30 \%, 60 \%$, and $100 \%$, respectively. The resistivity of the samples was explored using the two-electrode method during the capillary action. The effects of the coal gangue ceramsite contents on capillary water absorption capacity and resistivity of the matrix were verified. The variation of the resistivity of the matrix under the influence of capillary water transmission was analyzed. The results demonstrated that, for the unsaturated concrete, the resistivity of the matrix increased with the increment of the coal gangue ceramsite dosage. The electrical properties of the concrete were affected noticeably by the capillary water absorption of the matrix; the resistivity of the matrix dropped significantly under the capillary suction, which may be attributed to the formation of the new conductive channels caused by the absorbed water. The variation of the resistivity of the concrete under the capillary suction sustained the two-stage reduction curve. The ability of the capillary water absorption of concrete was enhanced with the addition of coal gangue ceramsite, compared to the traditional aggregates concrete, the initial sorptivity, and secondary sorptivity of the matrix increased by $47 \%$ and $16 \%$ with the $100 \%$ content of coal gangue ceramsite. However, during the process of the capillary suction, the resistivity of the coal gangue ceramic concrete was always greater than that of the concrete with traditional crushed aggregates.
\end{abstract}

\section{Introduction}

The electrical resistivity of the concrete is generally in the range of $1 \times 10^{1}-1 \times 10^{6} \Omega \cdot \mathrm{m}[1-3]$. In a completely dry state, the concrete can be attributed to insulating material [4]. However, due to the hydrophilicity of the cement-based material, the water in the surrounding circumstance can transport to the concrete through capillary action at the serviceability stage [5]. The ingress of moisture greatly enhances the electrical properties of the concrete, which may influence the progress of corrosion of embedded steel rebar and produce a negative effect on the durability of the structures [6-8]. For example, the stray current generated by subways can flow through reinforced concrete and produce an alteration of the potential distribution inside the matrix, which can accelerate the corrosion of the reinforcing bars [9-11]. In a humid environment, the electrical resistivity of the concrete may decrease due to the capillary water absorption and the negative impact of stray current will be exacerbated. Some signaling systems are also affected by the inadequate electrical resistivity of the concrete in the tunnel [12]. Therefore, the electrical properties of cementitious materials are concerned by some investigators [13-17]. Noort et al. [18] studied the effect of water to cement ratio on the electrical property of concrete, and the results showed that the electrical conductivity of the matrix increased with the increase of water to cement ratio. Sengul [19] investigated the electrical resistivity of concrete with limestone aggregate and gravel; the results showed that the electrical performance of the matrix was also affected by the type of aggregates. Hussain et al. [20] studied the influence of the fly ash on the electrical resistivity of the concrete; the results demonstrated that the electrical resistivity of the matrix could be enhanced by $120 \%$ with $30 \%$ (by mass) of the 
cement replaced by the fly ash. Liang et al. [21] suggested a new model for the electrical conductivity of cementitious material by regarding the pore size distribution. Capillary suction is one of the main ways of water penetration into concrete [22-27]. Therefore, the capillary water absorption capacity of concrete is an important factor regarding the changes in the electrical resistivity of the matrix. However, the investigations considering the effect of capillary water absorption on the electrical resistivity of concrete are still rare.

Coal gangues are solid wastes obtained during coal mining and processing $[28,29]$. A large amount of coal gangue was stored around the coaling areas and there was about 5 billion tons of coal gangue stored in Fuxin, China. Many investigators and engineers focused on the resource utilization of the coal gangue. As an important aspect of the utilization, coal gangue ceramsite demonstrates the characteristics of light weight and high strength. The coal gangue ceramsite are used as coarse aggregates in concrete for reducing the mining of the traditional aggregates [30]. Compared with traditional aggregates, the coal gangue ceramsite has larger porosity and stronger water absorption capacity. The addition of coal gangue ceramsite may enhance the capillary transportability of concrete, while from another perspective, due to the porosity of the coal gangue ceramsite, the resistivity of the matrix may be higher compared to traditional aggregate concrete; the higher resistivity of the concrete contributes to the durability of the structures. Therefore, it is necessary to explore the influence of coal gangue ceramsite on the resistivity of concrete in humid environment; the results may provide a meaningful experience for effectively reducing the negative influence of the stray current in subway.

In this paper, the capillary water absorption capacity of the concrete with the coal gangue ceramsite was studied according to ASTM C1585 [31]; the effect of the coal gangue ceramsite on sorptivity of the matrix was explored. The electrical resistance of the coal gangue ceramsite concrete specimens was measured by the two-electrode method, and the variation of the resistivity of the samples during the capillary water absorption process was analyzed. The influence of coal gangue ceramsite on concrete resistivity was investigated. The combined effects of coal gangue ceramsite on the capillary water absorption capacity and the electrical resistivity of the concrete were compared.

\section{Experimental Investigations}

2.1. Materials and Mixture Design. In this study, Ordinary Portland cement $42.5 R$ was used. Limestone aggregates with a maximum size of $20 \mathrm{~mm}$ were adopted as traditional coarse aggregates and the river sand with fineness modulus of 2.6 was used as fine aggregates. The specimens with traditional coarse aggregates were recorded as PC. For coal gangue ceramsite concrete, the limestone aggregates were replaced by the coal gangue ceramsite (see Figure 1(a)) with $30 \%$, $60 \%$, and $100 \%$ by volume and the specimens were recorded as CGC30, CGC60, and CGC100, respectively. The coal gangue ceramsite adopted in the experiment was the commercial product supplied by the factory in Fuxin, China (see Figure 1(b)). The properties of the coal gangue ceramsite and the traditional coarse aggregates were illustrated in Table 1. The mix proportions of the concrete were shown in Table 2.

2.2. Experimental Procedures. For each mixture, six cubic specimens of $100 \times 100 \times 100 \mathrm{~mm}$ were made. Three of the samples were prepared for the compressive strength test. The copper meshes were arranged on two sides of the other three samples during pouring; the samples were prepared for the capillary absorption and electrical resistance experiments. All the samples were cured for $28 \mathrm{~d}$ in the curing room.

The test equipment included a capillary water absorption device, as shown in Figure 2(a), and a two-electrode resistance measuring system. The resistance was measured by the LCR meter (at $100 \mathrm{kHz}, 4 \mathrm{~V}$ ), as shown in Figure 2(b). The specific test steps were as follows: (1) all the specimens were dried at $105^{\circ} \mathrm{C}$ in the thermostatic drying chamber to constant mass; (2) the four sides around the water absorption face of the samples were sealed with epoxy; (3) the mass and the resistance of the sample were measured in the dry state; (4) the sample was placed in the tank with a water immersion depth of $2-5 \mathrm{~mm}$ and kept in point contact with the supports; (5) the cumulative water absorbed and the resistance were recorded at different time intervals after removing the surface water by a dampened tissue.

The resistivity of the sample can be obtained by

$$
\rho=\frac{R A}{l}
$$

where $\rho$ means the resistivity of the matrix, $\mathrm{k} \Omega \cdot \mathrm{m} ; R$ means the resistance of the matrix, $\mathrm{k} \Omega ; A$ means the cross-sectional area of the sample, $\mathrm{m}^{2}$; $l$ means the length of the sample, $\mathrm{m}$.

\section{Results and Discussion}

3.1. Compressive Strength. In order to verify the effect of coal gangue ceramsite on the compressive strength of concrete, the uniaxial compression experiment was conducted according to the guidelines [32]. The values of the compressive strength of the specimens at $28 \mathrm{~d}$ are shown in Figure 3. For each type, the result is the average value of three samples.

From Figure 3, it can be seen that the compressive strength of the concrete is affected by the coal gangue ceramsite. The values of the PC, CGC30, CGC60, and CGC100 are 33.9 MPa, 33.6 MPa, 32.1 MPa, and 30.5 MPa, respectively. Compared to the value of $\mathrm{PC}$, the values of the CGC30, CGC60, and CGC100 decrease by $1 \%, 5 \%$, and $10 \%$, respectively. The phenomenon is also observed for the concrete with untreated coal gangue as coarse aggregates and the variation trend for the influence of coal gangue on compressive strength of the concrete agrees with the previous investigation performed by Li et al. [33], Zhou et al. [34], and Gao et al. [35]. It means that the compressive strength of the matrix is not obviously affected with coal gangue ceramsite replacement below $60 \%$; the decreasing of 


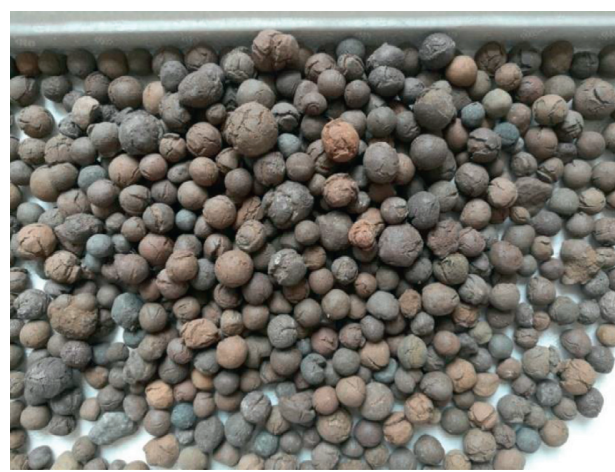

(a)

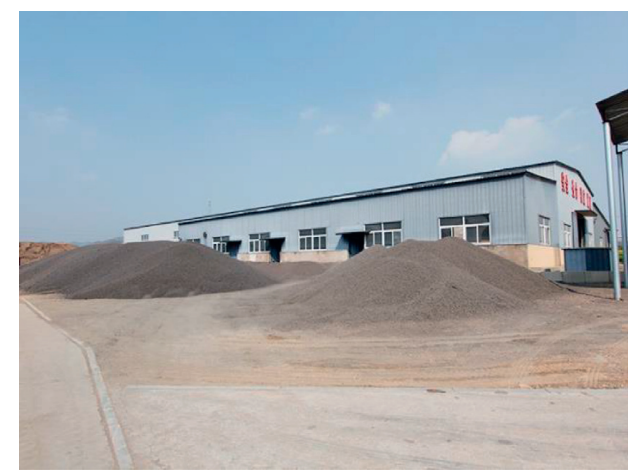

(b)

FIGURE 1: Coal gangue recycling: (a) coal gangue ceramsite; (b) production workshop.

TABle 1: Properties of the coarse aggregates.

\begin{tabular}{|c|c|c|c|c|c|c|}
\hline Types & $\begin{array}{l}\text { Bulk density } \\
\left(\mathrm{kg} / \mathrm{m}^{3}\right)\end{array}$ & $\begin{array}{l}\text { Rushing strength } \\
(\mathrm{MPa})\end{array}$ & $\begin{array}{c}\text { Crushed value } \\
(\%)\end{array}$ & $\begin{array}{c}24 \mathrm{~h} \text { water absorption } \\
(\%)\end{array}$ & $\begin{array}{c}\text { Coefficient of } \\
\text { softening }\end{array}$ & $\mathrm{LOI}^{\mathrm{a}}$ \\
\hline Coal gangue ceramsite & 844 & 6.2 & - & 8.4 & 0.98 & 0.03 \\
\hline $\begin{array}{l}\text { Traditional coarse } \\
\text { aggregate }\end{array}$ & 1450 & - & 9.8 & 0.8 & - & - \\
\hline
\end{tabular}

${ }^{\text {a }}$ Loss on ignition.

TABLE 2: Mix proportion of the concrete.

\begin{tabular}{lccccccc}
\hline Types & $\begin{array}{c}\text { Cement } \\
\left(\mathrm{kg} / \mathrm{m}^{3}\right)\end{array}$ & $\begin{array}{c}\text { Limestone } \\
\text { aggregates }\left(\mathrm{kg} / \mathrm{m}^{3}\right)\end{array}$ & $\begin{array}{c}\text { Coal gangue } \\
\text { ceramsite }\left(\mathrm{kg} / \mathrm{m}^{3}\right)\end{array}$ & $\begin{array}{c}\text { Fine aggregates } \\
\left(\mathrm{kg} / \mathrm{m}^{3}\right)\end{array}$ & $\begin{array}{c}\text { Fly ash } \\
\left(\mathrm{kg} / \mathrm{m}^{3}\right)\end{array}$ & $\begin{array}{c}\text { Water/additional } \\
\text { water }\left(\mathrm{kg} / \mathrm{m}^{3}\right)\end{array}$ & $\begin{array}{c}\text { Superplasticizer } \\
\left(\mathrm{kg} / \mathrm{m}^{3}\right)\end{array}$ \\
\hline PC & 390 & 850 & - & 850 & 155 & $273 / 0$ & 5.5 \\
CGC30 & 390 & 595 & 148 & 850 & 155 & $273 / 12.4$ & 5.5 \\
CGC60 & 390 & 340 & 297 & 850 & 155 & $273 / 24.9$ & 5.5 \\
CGC100 & 390 & - & 495 & 850 & 155 & $273 / 41.6$ \\
\hline
\end{tabular}

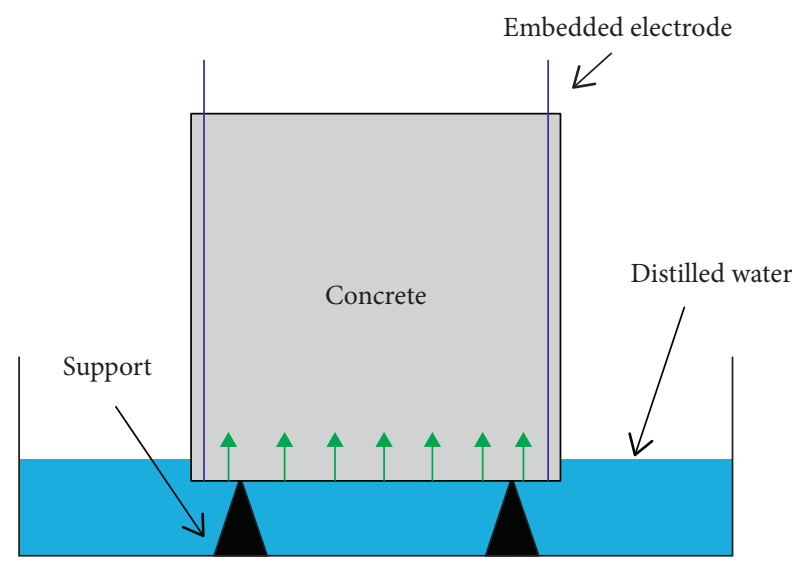

(a)

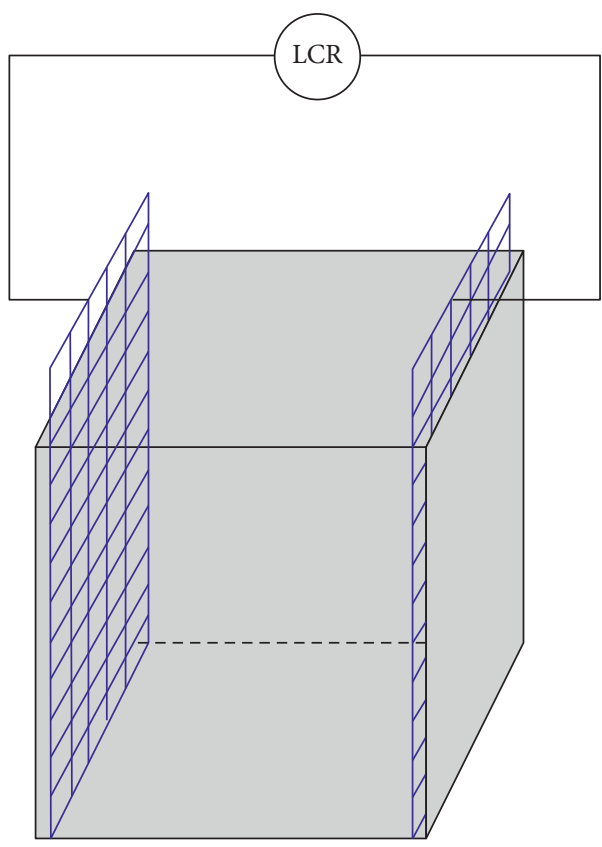

(b)

Figure 2: Experimental device: (a) schematic diagram of water absorption test; (b) schematic diagram of electrical resistance test. 


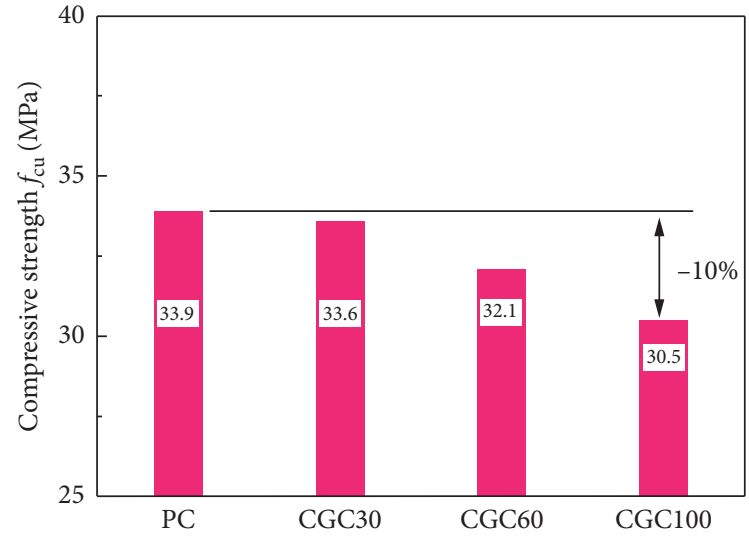

FIgURE 3: Comparison of the compressive strength.

the compressive strength of the matrix is significant with the coal gangue ceramsite replacement above $60 \%$.

3.2. Cumulative Water Absorption of Concrete. The results of the cumulative water absorption are illustrated in Figure 4. In the plots, each curve is the average result of three samples.

From Figure 4, it can be seen that the cumulative water absorption of the specimens increases with the extension of time. The increment rate of the cumulative water absorption of the matrix is rapid at the initial stage and then slows gradually. In order to compare the influence of coal gangue ceramsite on the capillary water absorption performance of concrete, the cumulative water absorption corresponding to the time $t$ of 0,360 , and $10080 \mathrm{~min}$ is taken as examples for comparative analysis. The cumulative water absorption of the specimens is shown in Figure 5.

From Figure 5, it can be seen that the cumulative water absorption of concrete specimens increases with the increase of coal gangue ceramsite dosage. When the time $t$ is $360 \mathrm{~min}$, the cumulative water absorption of PC, CGC30, CGC60, and CGC100 is $9.0 \mathrm{~g}, 10.6 \mathrm{~g}, 11.9 \mathrm{~g}$, and $11.8 \mathrm{~g}$. Compared to the value of $\mathrm{PC}$, the cumulative water absorption of CGC30, CGC60, and CGC100 increases by $18 \%, 32 \%$, and $31 \%$, respectively. When the time $t$ is $10080 \mathrm{~min}$, the cumulative water absorption of PC, CGC30, CGC60, and CGC100 is $12.3 \mathrm{~g}, 13.7 \mathrm{~g}, 14.9 \mathrm{~g}$, and $16.2 \mathrm{~g}$. Compared to the value of PC, the cumulative water absorption of CGC30, CGC60, and CGC100 increases by $11 \%, 21 \%$, and $32 \%$, respectively. This phenomenon may be attributed to the micropump function of the coal gangue ceramsite. The coal gangue ceramsite has a large porosity and relatively strong water absorption capacity; therefore, the coal gangue ceramsite may demonstrate a positive effect on the capillary water transmission.

3.3. Sorptivity of the Concrete. The cumulative volume of water absorbed per unit inflow area $i$ increases with the square root of elapsed time [26]. As a result, from the point of view of data fitting, the relationship between $i$ and $t^{1 / 2}$ is often given as

$$
i=a+S t^{1 / 2}
$$

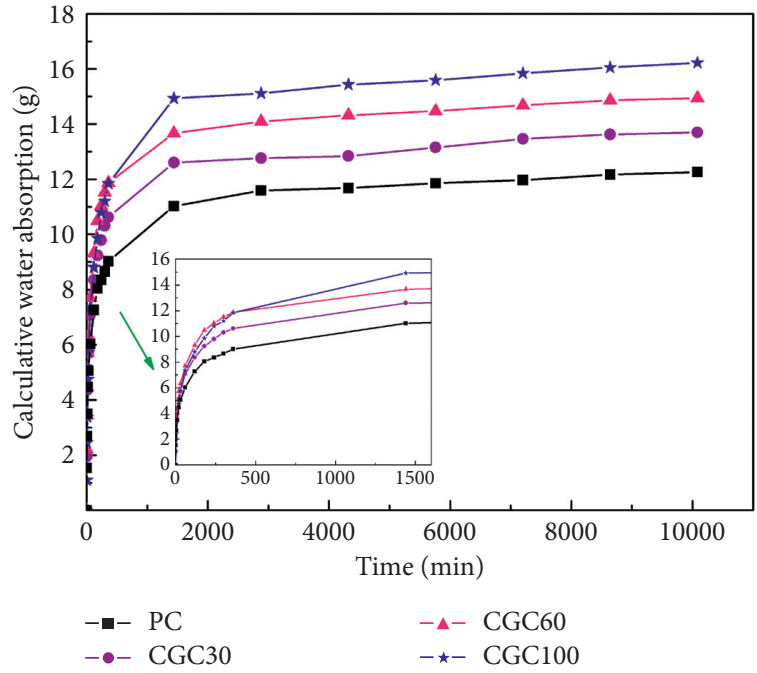

FIgURE 4: Cumulative water absorption of different specimens.

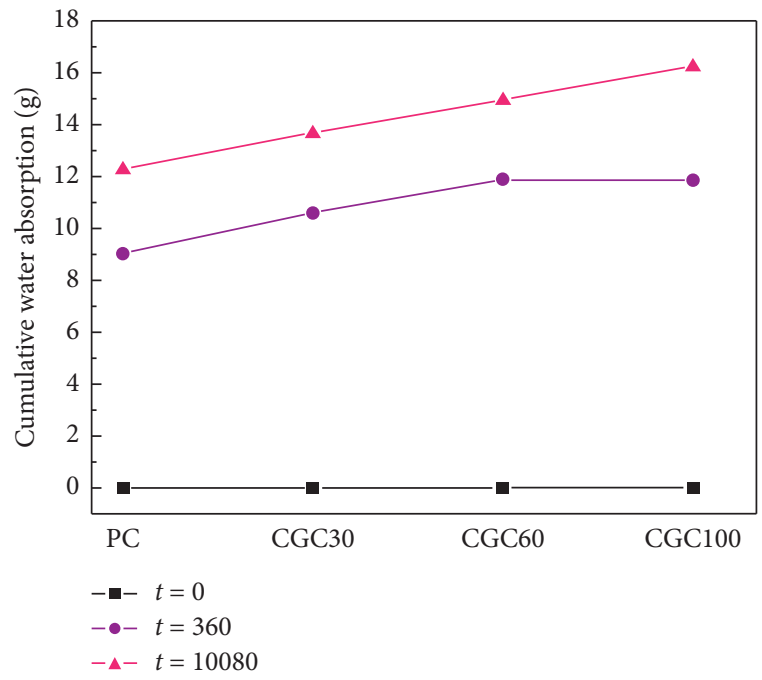

FIgURE 5: Effect of coal gangue ceramsite on cumulative water absorption of concrete.

where $a$ means a correction term; $S$ means the sorptivity, $\mathrm{mm} \cdot \mathrm{min}^{-1 / 2} ; t$ means the exposure time, min. The cumulative capillary water absorption height $i$ is calculated as

$$
i=\frac{\Delta m}{A_{c} \rho_{w}}
$$

where $\Delta m$ is the weight of absorbed water regarding the given time, $\mathrm{g} ; A_{\mathrm{c}}$ is the cross-section area of the specimen corresponding to the capillary water absorption, $\mathrm{mm}^{2} ; \rho_{\mathrm{w}}$ is the density of water, $\mathrm{g} / \mathrm{cm}^{3}$.

The relationship between water absorption height of the samples and square root of exposure time is shown in Figure 6.

From Figure 6, it can be seen that the relationship between the cumulative water absorption height and the square root of time demonstrates a two-stage change rule. The changing trend is in accordance with the guidelines [31] 


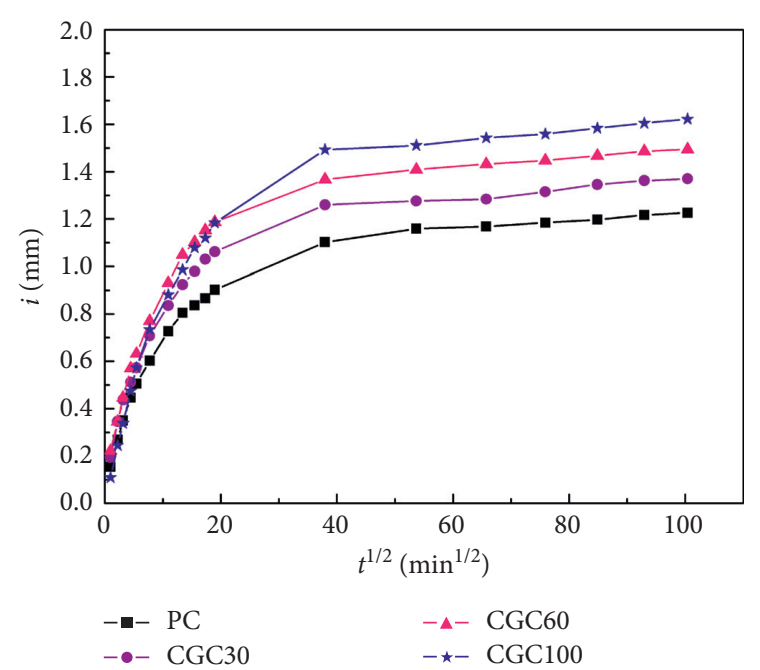

FIGURE 6: Relationship between water absorption height and square root of exposure time.

and the results investigated by Yang et al. [36] and Ding et al. [37] for the concrete with traditional coarse aggregates. The slopes of the two-liner portions of the plots are defined as the initial sorptivity $S_{1}$ and secondary sorptivity $S_{2}$. By using least-squares linear regression, the values of $S_{1}$ and $S_{2}$ of the samples can be obtained as listed in Table 3 .

From Table 3, the following can be seen:

The standard deviation corresponding to the fitting parameters is small. The coefficient values $(R 21 ; R 22)$ of six groups are larger than 0.950 ; the coefficient values $(R 21 ; R 22)$ of two groups are larger than 0.900 . The $R^{2}$ values of all the samples are greater than 0.900 , which sustained the existence of the linear relationship between the absorption and the square root of time.

The initial sorptivity $S_{1}$ of PC, CGC30, CGC60, and CGC100 is $0.0393 \mathrm{~mm} \cdot \mathrm{min}^{-1 / 2}, 0.0454 \mathrm{~mm} \cdot \mathrm{min}^{-1 / 2}$, $0.0523 \mathrm{~mm} \cdot \mathrm{min}^{-1 / 2}$, and $0.0576 \mathrm{~mm} \cdot \mathrm{min}^{-1 / 2}$. Compared to the value of PC, the initial sorptivity of CGC30, CGC60, and CGC100 increases by $16 \%, 33 \%$, and $47 \%$, respectively. The secondary sorptivity $S_{2}$ of PC, CGC30, CGC60, and CGC100 is $0.00184 \mathrm{~mm} \cdot \mathrm{min}^{-1 / 2}$, $0.00194 \mathrm{~mm} \cdot \mathrm{min}^{-1 / 2}, \quad 0.00202 \mathrm{~mm} \cdot \mathrm{min}^{-1 / 2}, \quad$ and $0.00213 \mathrm{~mm} \cdot \mathrm{min}^{-1 / 2}$. Compared to the value of PC, the secondary sorptivity of CGC30, CGC60, and CGC100 increases by $5 \%, 10 \%$, and $16 \%$, respectively. It means that the initial sorptivity $S_{1}$ and the secondary sorptivity $S_{2}$ of the concrete increase with the increase of coal gangue ceramsite dosage.

3.4. Prediction of Water Content Distribution. The capillary water absorption capacity of cementitious materials is usually described by Darcy's unsaturated fluid theory $[24,26]$.

$$
q=-K(\theta) \nabla \Psi,
$$

where $q$ means the flow velocity vector, $\Psi$ means the capillary potential energy, $K(\theta)$ means the function of hydraulic conductivity, and $\theta$ means the relative water content of the matrix, as follows:

$$
\theta=\frac{\Theta-\Theta_{i}}{\Theta_{s}-\Theta_{i}}
$$

Here, $\Theta$ denotes the moisture content of the matrix, $\Theta_{i}$ denotes the moisture content of the matrix before contact with water, and $\Theta s$ denotes the moisture content of the matrix under the saturated condition.

Assuming that only one exposed surface of the sample is in contact with water and the influence of gravity is also ignored, the one-dimensional capillary water absorption equation in concrete is obtained [38].

$$
\frac{\partial \theta}{\partial t}=\frac{\partial}{\partial x}\left(D(\theta) \frac{\partial \theta}{\partial x}\right)
$$

where $D(\theta)$ means the hydraulic diffusivity, while its physical meaning is different from the diffusion process of ions in solution under a concentration gradient [39]. The boundary condition $\theta=1$ at $x=0$ and the initial condition $\theta=0$ at $x>0$.

Using the Boltzmann transform $\phi=x / t^{1 / 2}$, equation (6) is rewritten as the ordinary differential equation

$$
-\frac{1}{2} \phi\left(\frac{\mathrm{d} \theta}{\mathrm{d} \phi}\right)=\frac{\mathrm{d}}{\mathrm{d} \theta}\left(D(\theta) \frac{\mathrm{d} \theta}{\mathrm{d} \phi}\right) .
$$

The approximate analytical solution of equation (7) was given by Parlange et al. [40] as

$$
2 \int_{\theta}^{1} \frac{D(a)}{a} \mathrm{~d} a=s \phi+\frac{B}{2} \phi^{2} .
$$

Here, $s$ means the relative sorptivity, given by

$$
s=\frac{S}{\Theta_{s}-\Theta_{i}} \cong\left(\int_{0}^{1}(1+\theta) D(\theta) \mathrm{d} \theta\right)^{1 / 2} .
$$

And $B$ is given by

$$
B=2-\frac{s^{2}}{\int_{0}^{1} D(\theta) \mathrm{d} \theta} .
$$

Set

$$
\lambda(\theta)=\int_{0}^{1} D(\theta) \mathrm{d} \theta .
$$

Equation (7) becomes

$$
B \phi^{2}+2 s \phi-4 \lambda(\theta)=0 .
$$

Finally, the water penetration depth can be obtained as

$$
x=\phi t^{1 / 2}=\frac{-s+\left[s^{2}+4 B \lambda(\theta)\right]^{1 / 2}}{B} t^{1 / 2} .
$$

In order to verify the relationship between the water penetration depth $x$ and water content $\theta$ at the given time, both the relative sorptivity $s$ and hydraulic diffusivity $D(\theta)$ are required. The parameters $B$ and $\lambda(\theta)$ can be obtained in terms of $D(\theta)$ and the sorptivity $S$ can be obtained by the experiment. The functional relationship between $D$ and $\theta$ is 
TABLE 3: Fitting results of the sorptivity

\begin{tabular}{|c|c|c|c|c|c|c|}
\hline Types & $S_{1}\left(\mathrm{~mm} \cdot \mathrm{min}^{-1 / 2}\right)$ & Standard deviation, $\sigma_{S 1}$ & $R_{1}^{2}$ & $S_{2}\left(\mathrm{~mm} \cdot \min ^{-1 / 2}\right)$ & Standard deviation, $\sigma_{S 2}$ & $R_{2}^{2}$ \\
\hline PC & 0.0393 & 0.0033 & 0.941 & 0.00184 & 0.00017 & 0.959 \\
\hline CGC30 & 0.0454 & 0.0032 & 0.956 & 0.00194 & 0.00020 & 0.947 \\
\hline CGC60 & 0.0523 & 0.0036 & 0.959 & 0.00202 & 0.00008 & 0.992 \\
\hline CGC100 & 0.0576 & 0.0039 & 0.960 & 0.00213 & 0.00011 & 0.986 \\
\hline
\end{tabular}

strongly nonlinear and is commonly approximated by the power function $[26,41,42]$.

$$
D(\theta)=D_{0} \theta^{n}
$$

Here, $D_{0}$ and $n$ are the fitted constants and $n$ is generally taken as 4 . Expression for $D_{0}$ and $B$ has been derived based on the expression law of $D(\theta)$ as

$$
\begin{aligned}
D_{0} & =\frac{(1+n)(2+n) s^{2}}{3+2 n}, \\
B & =\frac{1}{2(2+n)} .
\end{aligned}
$$

Subsequently, $\lambda(\theta)$ can be written as

$$
\lambda(\theta)=\frac{D_{0}}{n}\left(1-\theta^{n}\right)
$$

With equations (13)-(17) and the sorptivity obtained by experiment into equation (2), the water content distribution of the matrix can be predicted for any exposure time of a water resource.

Figure 7 shows the predictions of water content distribution after a series of time intervals for the matrix of PC, CGC30, CGC60, and CGC100.

From Figure 7, it can be seen that the water distribution of the concrete is affected by the addition of the coal gangue ceramsite. In order to analyze the influence of the coal gangue ceramsite on water penetration depth of the matrix quantitatively, take the case of $100 \mathrm{~min}$ exposure as an example (see Figure 8); the penetration depths of the PC, CGC30, CGC60, and CGC100 are $3.912 \mathrm{~mm}, 4.313 \mathrm{~mm}$, $4.826 \mathrm{~mm}$, and $5.014 \mathrm{~mm}$, respectively. Compared to the value of PC, the penetration depths of the CGC30, CGC60, and CGC100 increase by $10 \%, 23 \%$, and $28 \%$, respectively.

3.5. Electrical Resistivity of the Concrete. The results of the electrical resistivity of the specimens are illustrated in Figure 9.

From Figure 9, we can see that, due to the capillary water absorption, the resistivity of each group of specimens gradually decreases, and the curve shows a two-stage variation trend; that is, the curvature rapidly decreases in the initial stage and then slows down gradually. In order to compare the influence of coal gangue ceramsite on the resistivity property of concrete, the resistivity regarding the time $t$ of 0,360 , and $10080 \mathrm{~min}$ is taken as examples for comparative analysis. The resistivity of the specimens corresponding to the time $t$ of 0,360 , and $10080 \mathrm{~min}$ is shown in Figure 10.
From Figure 10, it can be seen that when the time $t$ is 0 min (completely dry state), the electrical resistivity of PC, CGC30, CGC60, and CGC100 is $0.331 \mathrm{k} \Omega \cdot \mathrm{m}, 0.378 \mathrm{k} \Omega \mathrm{m}$, $0.402 \mathrm{k} \Omega \mathrm{m}$, and $0.425 \mathrm{k} \Omega \mathrm{m}$. Compared to the value of $\mathrm{PC}$, the electrical resistivity of CGC30, CGC60, and CGC100 increases by $14 \%, 21 \%$, and $28 \%$, respectively. When the time $t$ is $360 \mathrm{~min}$, the electrical resistivity of PC, CGC30, CGC60, and CGC100 is $0.233 \mathrm{k} \Omega \cdot \mathrm{m}, \quad 0.243 \mathrm{k} \Omega \mathrm{m}$, $0.244 \mathrm{k} \Omega \mathrm{m}$, and $0.250 \mathrm{k} \Omega \mathrm{m}$. Compared to the value of $\mathrm{PC}$, the electrical resistivity of CGC30, CGC60, and CGC100 increases by $4 \%, 5 \%$, and $7 \%$, respectively. When the time $t$ is $10080 \mathrm{~min}$, the electrical resistivity of PC, CGC30, CGC60, and CGC100 is $0.196 \mathrm{k} \Omega \cdot \mathrm{m}, \quad 0.218 \mathrm{k} \Omega \mathrm{m}$, $0.220 \mathrm{k} \Omega \mathrm{m}$, and $0.214 \mathrm{k} \Omega \mathrm{m}$. Compared to the value of $\mathrm{PC}$, the electrical resistivity of CGC30, CGC60, and CGC100 increases by $11 \%, 12 \%$, and $9 \%$, respectively. It means that the electrical resistivity of the concrete is affected by the coal gangue ceramsite; the influence of aggregate type on electrical resistivity of the matrix is also observed by other researchers [3, 43-45]. The electrical resistivity of the unsaturated matrix has increased noticeably with the increase of coal gangue ceramsite dosage. Under the influence of capillary water suction, the electrical resistivity of coal gangue ceramsite concrete decreases significantly, while the values of the electrical resistivity of the concrete with coal gangue ceramsite are still greater than that of the traditional aggregate concrete specimens. In addition, according to the European Concrete Committee (CEB 192) [46-48], the concrete with the matrix resistivity below $0.200 \mathrm{k} \Omega \mathrm{m}$ is attributed to be under corrosion risk. During the experiment, only the electrical resistivity of the samples with the traditional coarse aggregates is below the specific value; therefore, the addition of the coal gangue ceramsite can reduce the corrosion risk of the concrete structures at the serviceability stage.

3.6. Relationship between the Variation of Water Absorption Capacity and Electrical Resistivity. The variation of cumulative capillary water absorption height-resistivity-time square root of each group of specimens is shown in Figure 11.

From Figure 11, it can be seen that the relationship between the changes of electrical resistivity of each group of specimens and the square root of time also demonstrates a two-stage change rule. With reference to the form of the sorptivity of the matrix, the initial change rate of electrical resistivity $C_{1}$ and the secondary change rate of electrical resistivity $C_{2}$ of the test samples can be obtained. The results are shown in Table 4.

From Table 4, the following can be seen: 

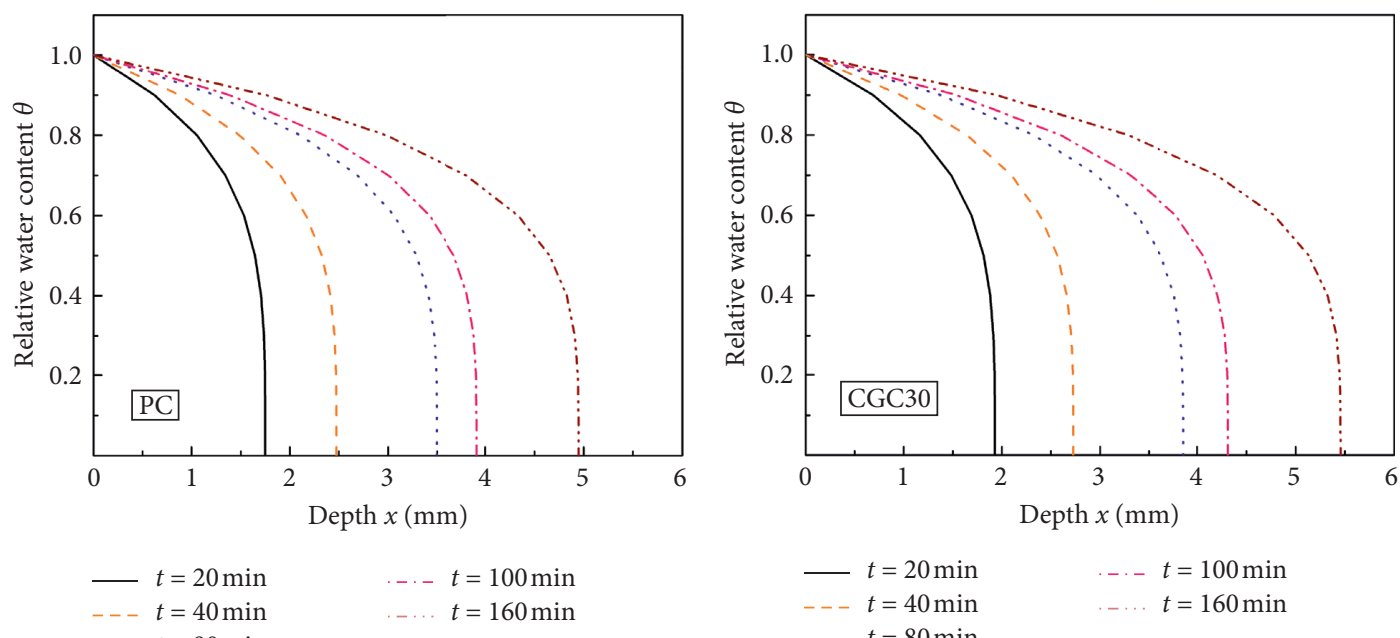

(a)

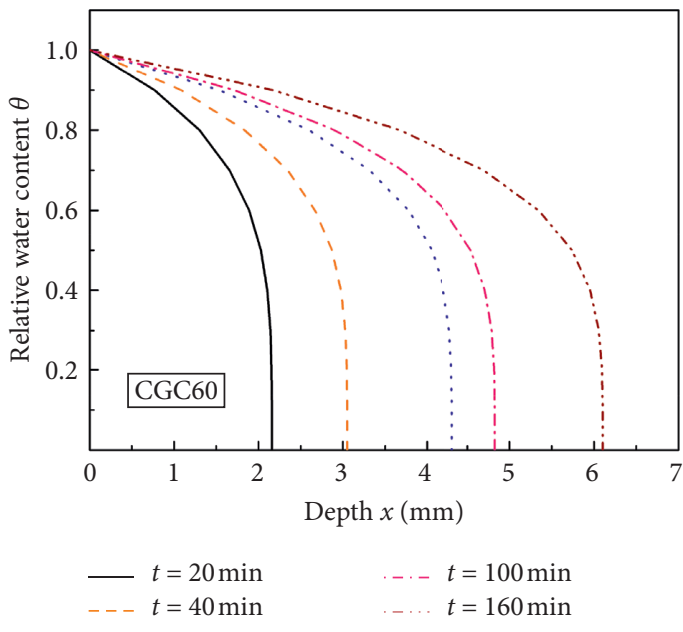

(c)

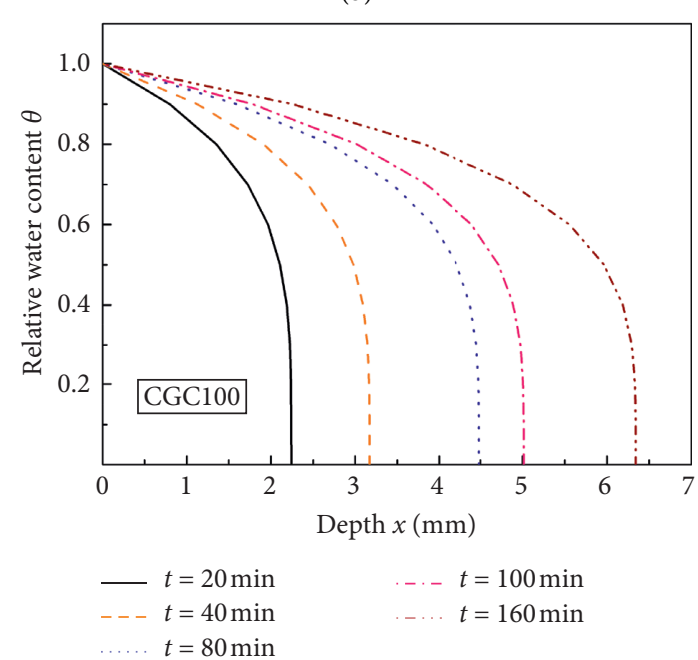

(d)

FIGURE 7: Prediction of water distribution of matrix at different times: (a) PC; (b) CGC30; (c) CGC60; (d) CGC100.

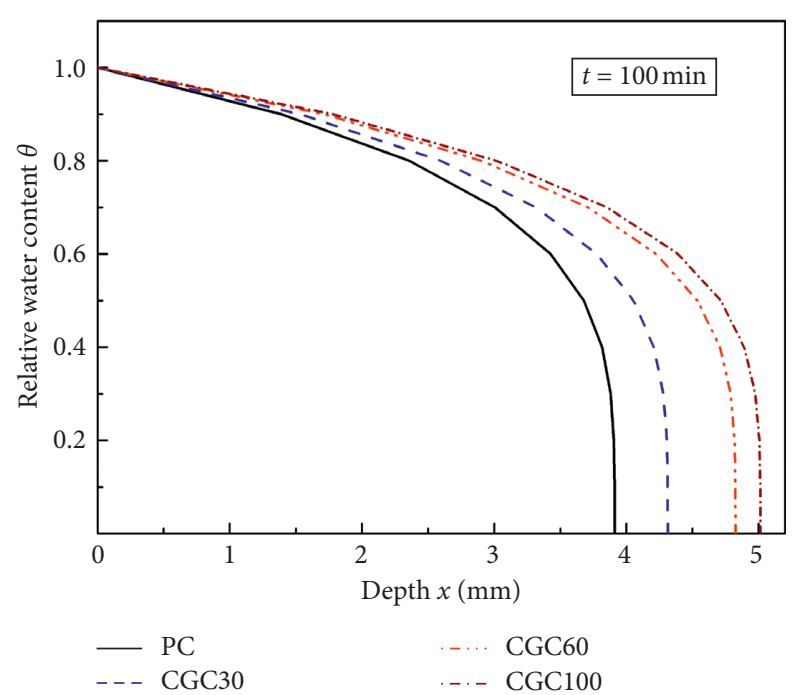

FIGURE 8: Influence of coal gangue ceramsite dosage on water penetration depth.

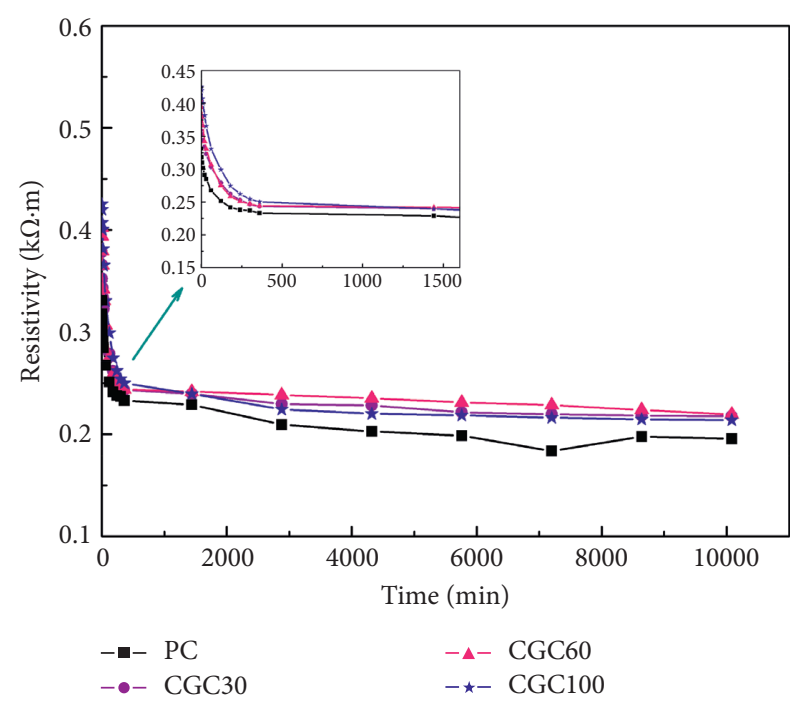

Figure 9: Resistivity of different specimens. 


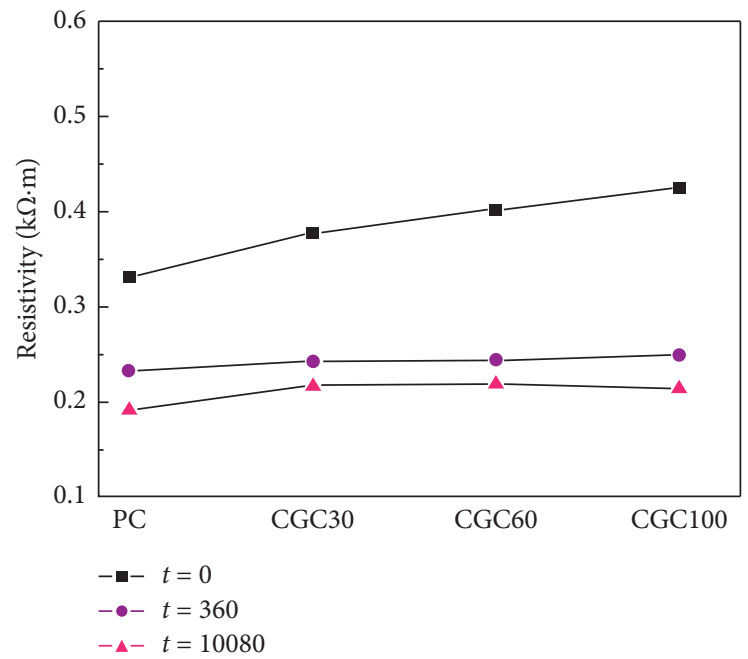

FiguRe 10: Influence of coal gangue ceramsite on electrical resistivity of concrete.

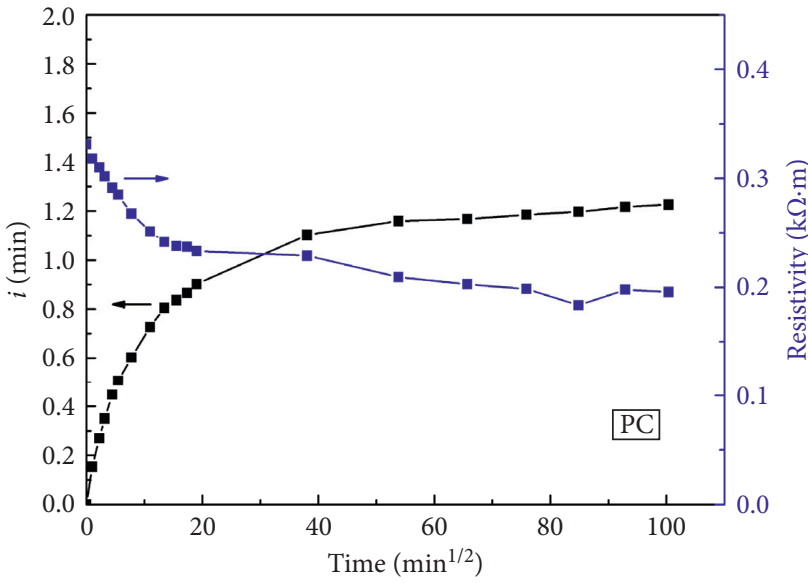

(a)

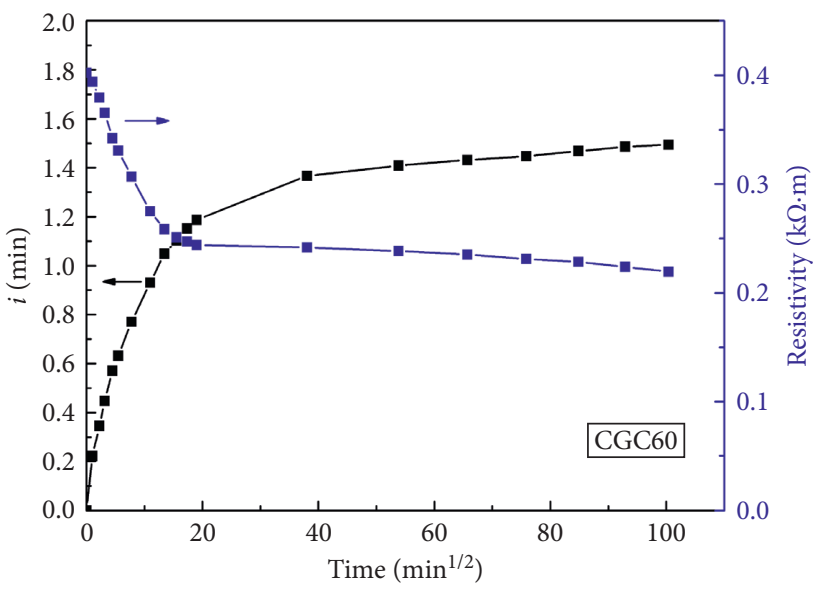

(c)

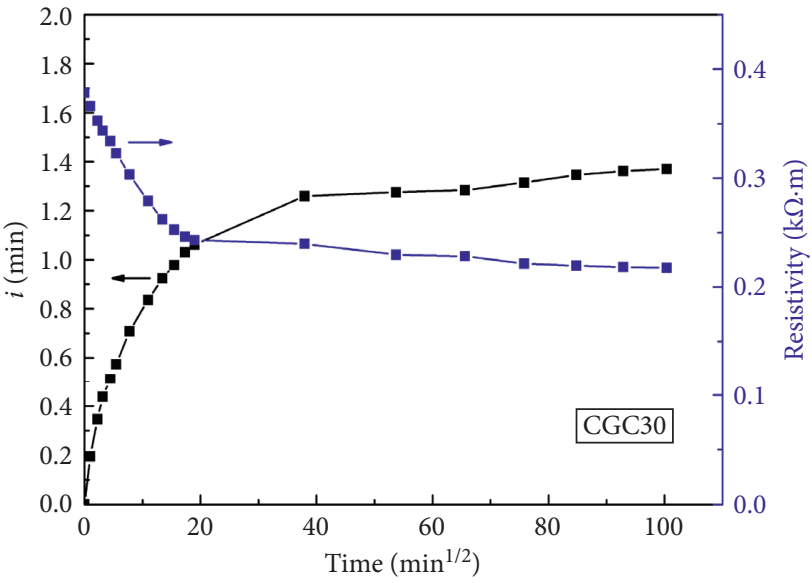

(b)

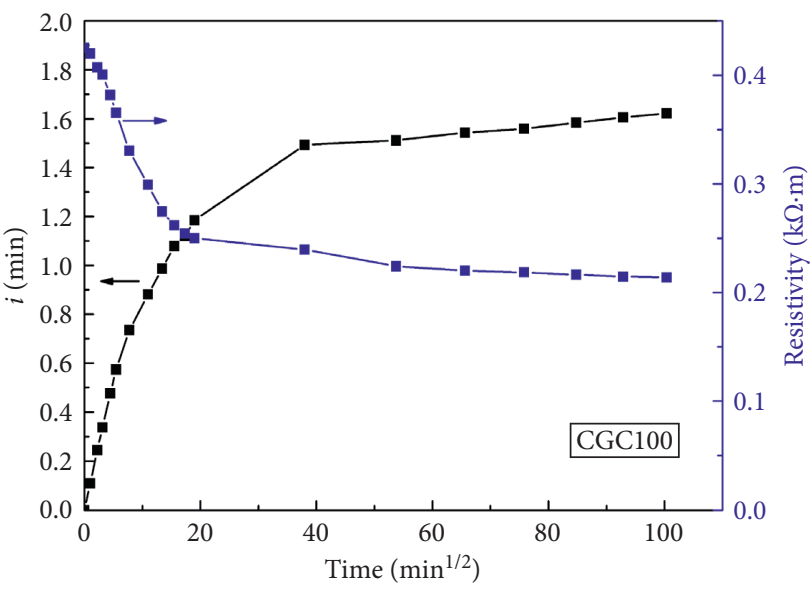

(d)

FIGURE 11: Cumulative water absorption height-resistivity-time curves: (a) PC; (b) CGC30; (c) CGC60; (d) CGC100. 
TABLE 4: Fitting results of the electrical resistivity rate.

\begin{tabular}{lccccc}
\hline Types & $C_{1} /(\mathrm{k} \Omega \cdot \mathrm{m}) \cdot \mathrm{min}^{-1 / 2}$ & Standard deviation, $\sigma_{C 1}$ & $R_{1}^{\prime 2}$ & $C_{2} /(\mathrm{k} \Omega \cdot \mathrm{m}) \cdot \mathrm{min}^{-1 / 2}$ & Standard deviation, $\sigma_{C 2}$ \\
\hline PC & -0.00512 & 0.00039 & 0.944 & -0.000536 & 0.000153 \\
CGC30 & -0.00727 & 0.00035 & 0.977 & -0.000350 & 0.710 \\
CGC60 & -0.00885 & 0.00062 & 0.953 & -0.000352 & 0.939 \\
CGC100 & -0.01018 & 0.00048 & 0.978 & -0.000369 & 0.000039 \\
\hline
\end{tabular}

The standard deviation regarding the fitting parameters is really small. The coefficient values $\left(R^{\prime} 21\right.$ and $\left.R^{\prime} 22\right)$ of six groups are larger than 0.900 ; the coefficient values $(R / 21$ and $R^{\prime} 22$ ) of only two groups are greater than 0.700 . It means that the curve of the electrical resistivity-square root of time substantiates the two-stage variation trends. The initial change rate of electrical resistivity $C_{1}$ of $\mathrm{PC}$, CGC30, CGC60, and CGC100 is $-0.00512(\mathrm{k} \Omega \mathrm{m})$. $\min ^{-1 / 2},-0.00727(\mathrm{k} \Omega \mathrm{m}) \cdot \mathrm{min}^{-1 / 2},-0.00885(\mathrm{k} \Omega \mathrm{m})$. $\min ^{-1 / 2}$, and $-0.01018(\mathrm{k} \Omega \mathrm{m}) \cdot \mathrm{min}^{-1 / 2}$. Compared to the value of $\mathrm{PC}$, the absolute initial change rate of electrical resistivity of CGC30, CGC60, and CGC100 increases by $42 \%, 73 \%$, and $99 \%$, respectively. The secondary change rate of electrical resistivity $D_{2}$ of PC, CGC30, CGC60, and CGC100 is $-0.000536(\mathrm{k} \Omega \cdot \mathrm{m})$. $\min ^{-1 / 2},-0.000350(\mathrm{k} \Omega \mathrm{m}) \cdot \mathrm{min}^{-1 / 2},-0.000352(\mathrm{k} \Omega \mathrm{m})$. $\mathrm{min}^{-1 / 2}$, and $-0.000369(\mathrm{k} \Omega \mathrm{m}) \cdot \mathrm{min}^{-1 / 2}$. Compared to the value of $\mathrm{PC}$, the absolute secondary change rate of electrical resistivity of CGC30, CGC60, and CGC100 decreases by $35 \%, 34 \%$, and $31 \%$, respectively. It means that the initial change rate of electrical resistivity $C_{1}$ would increase significantly with the increase of the coal gangue ceramsite content, while the secondary change rate of electrically resistivity $C_{2}$ reduces with the increase of the coal gangue ceramsite dosage.

3.7. Relationship between Cumulative Water Absorption and Electrical Resistivity. The electrical resistivity of the samples under capillary water absorption can be simplified as a parallel connection of two resistors, as shown in Figure 12.

With parallel form, the equivalent electrical resistance can be obtained by [49]

$$
\frac{1}{R}=\frac{1}{R_{1}}+\frac{1}{R_{2}}
$$

where $R$ means the equivalent electrical resistance, $\mathrm{k} \Omega ; R_{1}$ means the electrical resistance of the matrix without the influence of capillary water absorption, $k \Omega ; R_{2}$ means the electrical resistance of the matrix under capillary water absorption, $k \Omega$.

By considering equation (1), equation (18) can be rewritten as

$$
\frac{A}{\rho l}=\frac{A_{1}}{\rho_{1} l}+\frac{A_{2}}{\rho_{2} l},
$$

where $A_{1}$ means the cross-sectional area of the matrix without the influence of capillary water absorption, $\mathrm{m}^{2} ; \rho_{1}$ means the electrical resistivity of the matrix without the influence of capillary water absorption, $\mathrm{k} \Omega \cdot \mathrm{m} ; A_{2}$ means the cross-sectional area of the matrix under capillary water absorption, $\mathrm{m}^{2} ; \rho_{2}$ means the electrical resistivity of the matrix under capillary water absorption, $\mathrm{k} \Omega \cdot \mathrm{m}$.

$A_{1}$ and $A_{2}$ are given by

$$
\begin{aligned}
& A_{1}=l(l-i), \\
& A_{2}=l i .
\end{aligned}
$$

Subsequently, equation (19) can be written as

$$
\frac{l}{\rho}=\frac{l-i}{\rho_{1}}+\frac{i}{\rho_{2}} .
$$

Finally, equation (22) is obtained as

$$
\rho=\frac{1}{1+\left(\left(\rho_{1}-\rho_{2}\right) / \rho_{2} l\right) i \rho_{1}} .
$$

The relationship between cumulative water absorption height and variation of the specimen resistivity with different coal gangue ceramsite dosage is shown in Figure 13.

From Figure 13, we can see that the resistivity of each group of specimens gradually decreases with the increase of the cumulative water absorption height. The curve can be divided into three stages (take the curve of CGC100 as an example, as shown in Figure 13):

Stage I: the electrical resistivity of the concrete decreases slowly. It may be attributed to the fact that, at the initial stage of capillary water suction, the cumulative water absorption height is very small, and the contribution of the capillary water to the electrical resistivity of the matrix is limited.

Stage II: the electrical resistivity of the matrix decreases significantly. As the capillary water absorption, the cumulative water absorption height of the matrix increases. The water entering the matrix begins to overlap and form a conductive network. When the water content inside the material increases to the percolation threshold, the local conductive networks contact each other, and the interconnected conductive channels are formed inside the matrix. Thereby the electrical resistivity of the concrete reduces notably. The phenomenon can also be explained according to equation (23). The relationship between $i$ and $\rho$ is inversely proportional. With the increase of $i$, the electrical resistivity $\rho$ drops noticeably.

Stage III: the electrical resistivity demonstrates a certain degree of reduction. This may be due to the fact that the capillary water absorption rate is quite small at this stage; the water distribution in the matrix is more homogeneous which further reduces the resistivity of the matrix. 


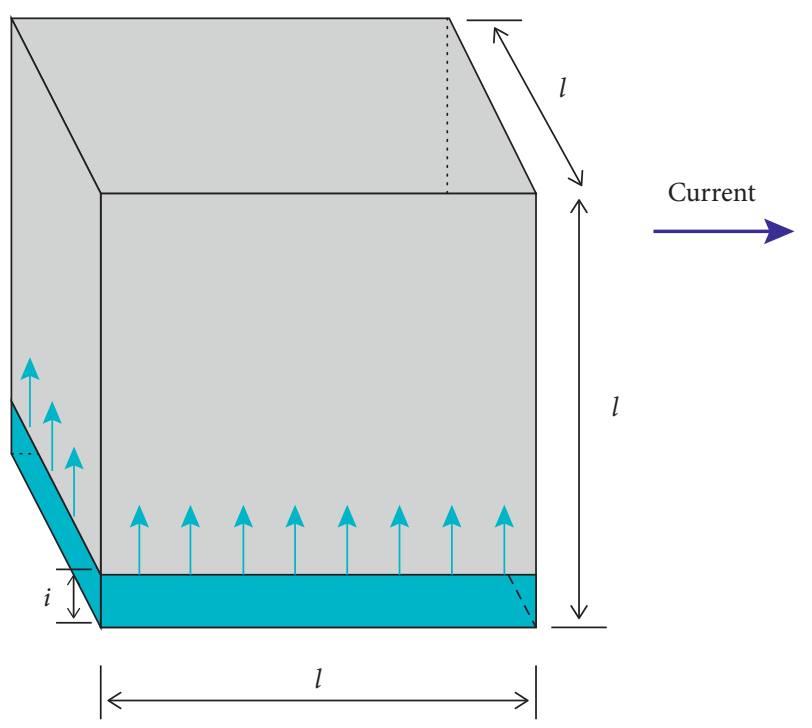

(a)

(b)

FIGURE 12: Schematic diagram of the electrical resistivity of the matrix under capillary water absorption: (a) capillary water absorption process; (b) parallel connection of two resistors.

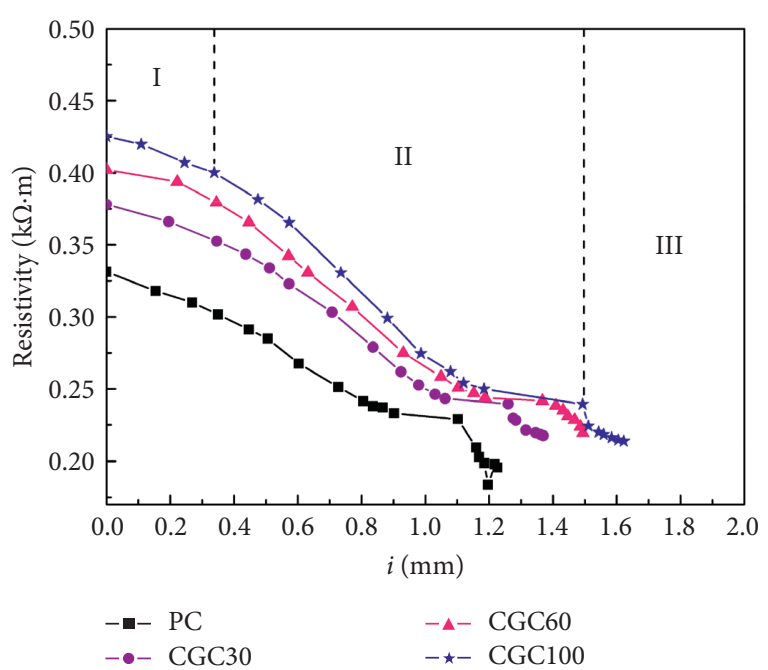

FIGURE 13: Relationship between resistivity and cumulative water absorption height.

In addition, we can see that, with the addition of coal gangue ceramsite, the electrical resistivity of the matrix demonstrates an advantage than the concrete with traditional aggregates under the action of capillary water suction. It means that the coal gangue ceramsite demonstrates positive effects on the electrical resistivity of concrete even though the addition of coal gangue ceramsite may contribute to the capillary water absorption capacity of the concrete.

\section{Conclusions}

The following conclusions can be obtained according to the experimental and analytical exploration:
(1) The electrical resistivity of the unsaturated concrete increases obviously with the increment of coal gangue ceramsite dosage.

(2) The addition of the coal gangue ceramsite demonstrates a significant influence on the capillary water absorption capacity of concrete. With the increase of the coal gangue ceramsite content, the water absorption capacity of the matrix increases. The water absorption rate of the coal gangue ceramsite concrete conforms to the two-stage change law. The initial water absorption rate and the secondary water absorption rate increase with the increment of coal gangue ceramsite content.

(3) Due to the capillary action, more conductive channels are formed inside the concrete and the electrical resistivity of the matrix drops dramatically.

(4) Under the capillary action, the variation of the electrical resistivity of the concrete is affected by the dosage of coal gangue ceramsite. The incorporation of coal gangue ceramsite can enhance the water transmission capacity of the matrix to a certain extent and reduce its electrical resistivity, but the electrical resistivity of the matrix is still greater than that of the corresponding traditional aggregate concrete.

(5) In a humid environment, the coal gangue ceramsite concrete can maintain a relatively high electrical resistivity, which may reduce the negative influence of stray current and improve the durability of the structures.

\section{Data Availability}

The data used to support the investigations of this study are available from the corresponding author upon request. 


\section{Conflicts of Interest}

The authors declare that they have no conflicts of interest regarding the publication of this paper.

\section{Acknowledgments}

The authors gratefully acknowledge the Educational Department of Liaoning Province, China (Grant LJ2019QL010), National Natural Science Foundation of China (Grant 52074144), and Liaoning Technical University, China (Grant LNTU20TD-12).

\section{References}

[1] D. Maguire and M. Olen, "Report on an investigation into the electrical properties of concrete," Transactions of the South African Institute of Electrical Engineers, vol. 31, no. 11, pp. 301-313, 1940.

[2] X. Zeng, C. Ling, Z. Pan et al., "Influence of capillary water absorption on resistivity of cement mortar," Journal of Building Materials, vol. 21, no. 5, pp. 714-719, 2018, in Chinese.

[3] A. Pejman and G. Rishi, "Electrical resistivity of concrete for durability evaluation: a review," Advances in Materials Science and Engineering, vol. 2017, Article ID 8453095, 30 pages, 2017.

[4] H. W. Whittington, J. Mccarter, and M. C. Forde, "The conduction of electricity through concrete," Magazine of Concrete Research, vol. 33, no. 114, pp. 48-60, 1981.

[5] C. Hall and W. D. Hoff, Water Transport in Brick, Stone and Concrete, CRC Press, Boca Raton, FL, USA, 2011.

[6] A. M. Neville, Properties of Concrete, Longman London, London, UK, 1995.

[7] R. Spragg, C. Villani, K. Snyder, D. Bentz, J. W. Bullard, and J. Weiss, "Factors that influence electrical resistivity measurements in cementitious systems," Transportation Research Record: Journal of the Transportation Research Board, vol. 2342, no. 1, pp. 90-98, 2013.

[8] K. Hornbostel, C. K. Larsen, and M. R. Geiker, "Relationship between concrete resistivity and corrosion rate - a literature review," Cement and Concrete Composites, vol. 39, pp. 60-72, 2013.

[9] B. Luca, E. Bernhard, P. Pietro et al., Corrosion of Steel in Concrete: Prevention, Diagnosis, Repair, Wiley-VCH, Hoboken, NJ, USA, 2004.

[10] L. Bertolini, M. Carsana, and P. Pedeferri, "Corrosion behaviour of steel in concrete in the presence of stray current," Corrosion Science, vol. 49, no. 3, pp. 1056-1068, 2007.

[11] A. O. S. Solgaard, M. Carsana, M. R. Geiker, A. Küter, and L. Bertolini, "Experimental observations of stray current effects on steel fibres embedded in mortar," Corrosion Science, vol. 74, pp. 1-12, 2013.

[12] C.-H. Lee and H.-M. Wang, "Effects of grounding schemes on rail potential and stray currents in Taipei rail transit systems," IEE Proceedings - Electric Power Applications, vol. 148, no. 2, pp. 148-154, 2001.

[13] J. F. Lataste, C. Sirieix, D. Breysse, and M. Frappa, "Electrical resistivity measurement applied to cracking assessment on reinforced concrete structures in civil engineering," NDT \& $E$ International, vol. 36, no. 6, pp. 383-394, 2003.

[14] C.-T. Chen, J.-J. Chang, and W.-C. Yeih, "The effects of specimen parameters on the resistivity of concrete," Construction and Building Materials, vol. 71, pp. 35-43, 2014.
[15] Y.-C. Lim, T. Noguchi, and C.-G. Cho, "A quantitative analysis of the geometric effects of reinforcement in concrete resistivity measurement above reinforcement," Construction and Building Materials, vol. 83, pp. 189-193, 2015.

[16] A. Lübeck, A. L. G. Gastaldini, D. S. Barin, and H. C. Siqueira, "Compressive strength and electrical properties of concrete with white Portland cement and blast-furnace slag," Cement and Concrete Composites, vol. 34, no. 3, pp. 392-399, 2012.

[17] J. Sanchez, C. Andrade, J. Torres et al., "Determination of reinforced concrete durability with on-site resistivity measurements," Materials and Structures, vol. 50, no. 1, pp. 1-9, 2017.

[18] R. Noort, M. Hunger, and P. Spiesz, "Long-term chloride migration coefficient in slag cement-based concrete and resistivity as an alternative test method," Construction and Building Materials, vol. 43, 2016.

[19] O. Sengul, "Use of electrical resistivity as an indicator for durability," Construction and Building Materials, vol. 73, pp. 434-441, 2014.

[20] S. E. Hussain, "Corrosion resistance performance of fly ash blended cement concrete," ACI Materials Journal, vol. 91, no. 3, pp. 264-272, 1994.

[21] K. Liang, X. Zeng, X. Zhou, F. Qu, and P. Wang, "A new model for the electrical conductivity of cement-based material by considering pore size distribution," Magazine of Concrete Research, vol. 69, no. 20, pp. 1067-1078, 2017.

[22] J. Bao, S. Li, P. Zhang et al., "Influence of the incorporation of recycled coarse aggregate on water absorption and chloride penetration into concrete," Construction and Building Materials, vol. 239, Article ID 117845, 2020.

[23] J. Bao, S. Xue, P. Zhang et al., "Coupled effects of sustained compressive loading and freeze-thaw cycles on water penetration into concrete," in Structural ConcreteWiley, Hoboken, NJ, USA, 2020.

[24] L. Wang and S. Li, "Capillary absorption of concrete after mechanical loading," Magazine of Concrete Research, vol. 66, no. 8, pp. 420-431, 2014.

[25] N. S. Martys and C. F. Ferraris, "Capillary transport in mortars and concrete," Cement and Concrete Research, vol. 27, no. 5, pp. 747-760, 1997.

[26] C. Hall, "Water sorptivity of mortars and concretes: a review," Magazine of Concrete Research, vol. 41, no. 147, pp. 51-61, 1989.

[27] P. Zhang, F. H. Wittmann, M. Vogel, H. S. Müller, and T. Zhao, "Influence of freeze-thaw cycles on capillary absorption and chloride penetration into concrete," Cement and Concrete Research, vol. 100, pp. 60-67, 2017.

[28] X. Y. Cong, S. Lu, Y. Yao, and Z. Wang, "Fabrication and characterization of self-ignition coal gangue autoclaved aerated concrete," Materials \& Design, vol. 97, pp. 155-162, 2016.

[29] Y. Z. Zhang, Q. H. Wang, M. Zhou et al., "Mechanical properties of concrete with coarse spontaneous combustion gangue aggregate (SCGA): experimental investigation and prediction methodology," Construction and Building Materials, vol. 255, pp. 1-15, 2012.

[30] H. Li, Comprehensive Utilization of Coal Gangue, Chemical Industry Press, Beijing, China, 2010, in Chinese.

[31] ASTM International, Standard Test Method for Measurement of Rate of Absorption of Water by Hydraulic-Cement Concretes, ASTM International, West Conshohocken, PA, USA, 1585.

[32] Natioinal Standards of the People's Republic of China (GB/T 50082), Standard for Test Methods of Long-Term Performance 
and Durability of Ordinary Concrete, China Architecture \& Building Press, Beijing, China, 2009.

[33] G. Li, B. Wang, and M. Zhou, "Study on flexural properties of reinforced spontaneous combustion gangue concrete beams," Periodica Polytechnica. Civil Engineering, vol. 62, no. 1, pp. 206-218, 2018.

[34] M. Zhou, Y. Dou, Y. Zhang, Y. Zhang, and B. Zhang, "Effects of the variety and content of coal gangue coarse aggregate on the mechanical properties of concrete," Construction and Building Materials, vol. 220, pp. 386-395, 2019.

[35] S. Gao, G. Zhao, L. Guo, L. Zhou, and K. Yuan, "Utilization of coal gangue as coarse aggregates in structural concrete," Construction and Building Materials, vol. 268, Article ID 121212, 2021.

[36] L. Yang, G. Liu, D. Gao, and C. Zhang, "Experimental study on water absorption of unsaturated concrete: $\mathrm{w} / \mathrm{c}$ ratio, coarse aggregate and saturation degree," Construction and Building Materials, vol. 272, Article ID 121945, 2021.

[37] X. Ding, X. Liang, Y. Zhang, Y. Fang, J. Zhou, and T. Kang, "Capillary water absorption and micro pore connectivity of concrete with fractal analysis," Crystals, vol. 10, no. 10, p. 892, 2020.

[38] D. Lockington, J.-Y. Parlange, and P. Dux, "Sorptivity and the estimation of water penetration into unsaturated concrete," Materials and Structures, vol. 32, no. 5, pp. 342-347, 1999.

[39] C. Hall, "Anomalous diffusion in unsaturated flow: fact or fiction?" Cement and Concrete Research, vol. 37, no. 3, pp. 378-385, 2007.

[40] J.-Y. Parlange, I. G. Lisle, S. N. Prasad, and M. J. M. Römkens, "Wetting front analysis of the nonlinear diffusion equation," Water Resources Research, vol. 20, no. 5, pp. 636-638, 1984.

[41] C. Leech, D. Lockington, and P. Dux, "Unsaturated diffusivity functions for concrete derived from NMR images," Materials and Structures, vol. 36, no. 6, pp. 413-418, 2003.

[42] J. Bao and L. Wang, "Effect of short-term sustained uniaxial loadings on water absorption of concrete," Journal of Materials in Civil Engineering, vol. 29, no. 3, Article ID 04016234, 2017.

[43] W. Morris, E. I. Moreno, and A. A. Sagüés, "Practical evaluation of resistivity of concrete in test cylinders using a Wenner array probe," Cement and Concrete Research, vol. 26, no. 12, pp. 1779-1787, 1996.

[44] Y. Liu and F. Presuelmoreno, "Effect of elevated temperature curing on compressive strength and electrical resistivity of concrete with fly ash and GGBS," ACI Materials Journal, vol. 111, no. 5, pp. 531-542, 2014.

[45] N. Singh and S. P. Singh, "Electrical resistivity of self consolidating concretes prepared with reused concrete aggregates and blended cements," Journal of Building Engineering, vol. 25, Article ID 100780, 2019.

[46] CEB-FIP, "Diagnosis and assessment of concrete structures-state of the art report," CEB Bulletins, vol. 192, 1989.

[47] P. K. Mehta and P. J. M. Monteiro, Concrete: Microstructure, Properties, and Materials, McGraw-Hill Education, New York, NY, USA, 2014.

[48] D. V. Ribeiro, J. A. Labrincha, and M. R. Morelli, "Effect of the addition of red mud on the corrosion parameters of reinforced concrete," Cement and Concrete Research, vol. 42, no. 1, pp. 124-133, 2012.

[49] W. Bauer and G. D. Westfall, University Physics with Modern Physics, McGraw-Hill, New York, NY, USA, 2011. 